\title{
Retraction Note to: Diffusion-weighted MR imaging of locally advanced breast carcinoma: the optimal time window of predicting the early response to neoadjuvant chemotherapy
}

\author{
Li Yuan ${ }^{1,2}$, Jian-Jun Li $i^{2}$, Chang-Qing Li' ${ }^{2}$, Cheng-Gong Yan ${ }^{1}$, Ze-Long Cheng ${ }^{1}$, Yuan-Kui Wu' ${ }^{1}$ Peng Hao', \\ Bing-Quan Lin ${ }^{1}$ and Yi-Kai Xu ${ }^{1 *}$
}

Retraction Note to: Cancer Imaging 18, 38 (2018). https:/doi.org/10.1186/s40644-018-0173-5

The Editors-in-Chief have retracted this article. After publication concerns were raised that there were discrepancies in the reporting of the number of NACT cycles the patients underwent. The authors were given the opportunity to provide an explanation but have not responded to any correspondence regarding this matter. The Editors-in-Chief therefore no longer have confidence in the results presented.

Li Yuan, Jian-Jun Li, Chang-Qing Li, Cheng-Gong Yan, Ze-Long Cheng, Yuan-Kui Wu, Peng Hao, Bing-Quan Lin and $\mathrm{Yi}-\mathrm{Kai} \mathrm{Xu}$ have not responded to any correspondence from the editor/publisher about this retraction.

\footnotetext{
Author details

'Department of Medical Imaging Center, Nanfang Hospital, Southern Medical University, \#1838 Guangzhou Avenue North, Guangzhou City 510,515, Guangdong Province, China. ${ }^{2}$ Department of Radiology, Hainan General Hospital, Haikou 570,311, Hainan Province, China.
}

Published online: 25 November 2021

\footnotetext{
The original article can be found online at https://doi.org/10.1186/s40644018-0173-5

* Correspondence: xuyikai1997@126.com

'Department of Medical Imaging Center, Nanfang Hospital, Southern Medical University, \#1838 Guangzhou Avenue North, Guangzhou City 510,515, Guangdong Province, China

Full list of author information is available at the end of the article
}

(c) The Author(s). 2021 Open Access This article is licensed under a Creative Commons Attribution 4.0 International License, which permits use, sharing, adaptation, distribution and reproduction in any medium or format, as long as you give appropriate credit to the original author(s) and the source, provide a link to the Creative Commons licence, and indicate if changes were made. The images or other third party material in this article are included in the article's Creative Commons licence, unless indicated otherwise in a credit line to the material. If material is not included in the article's Creative Commons licence and your intended use is not permitted by statutory regulation or exceeds the permitted use, you will need to obtain permission directly from the copyright holder. To view a copy of this licence, visit http://creativecommons.org/licenses/by/4.0/. The Creative Commons Public Domain Dedication waiver (http://creativecommons.org/publicdomain/zero/1.0/) applies to the data made available in this article, unless otherwise stated in a credit line to the data. 